\title{
Managing clinical trials in Asia: Issues, threats, opportunities and approaches
}

\author{
Sayeeda Rahman ${ }^{1}$, Md. Anwarul Azim Majumder ${ }^{2}$
}

${ }^{1,2}$ Lecturer, Department of Clinical Sciences, School of Medical Sciences, University of Bradford, West Yorkshire, Bradford, UK.

Clinical trials provide health and safety benefits to patients by offering new treatments more quickly in the market. In the past, clinical trials were largely conducted in the Western countries. In recent years, economical crises in the USA and Europe, escalating costs, and limited patient pools forced pharmaceutical and biotech companies to look for emerging markets in Asia. ${ }^{1}$ The research costs are significantly less in Asian countries and the region offers the advantage of a larger and more genetically diverse population, many of whom have never been treated for their condition. ${ }^{1-4}$ Several Asian countries, especially India, Malaysia, Thailand, Singapore and China, have become prominent outsourcing locations for clinical research, especially for phase 3 clinical trials. ${ }^{1-5}$ However, phase 1 clinical trials are mostly conducted in developed countries - the top three countries that did the most of the phase 1 clinical trials were USA, Canada and UK. ${ }^{1}$

We have analyzed the clinical studies registered in the ClinicalTrials.gov ${ }^{6}$ from 2001-12 by Asian* and WHO SEAR countries**, and found that Asian countries had the global share of $18.2 \%$ of the clinical trials and WHO SEAR countries had only $3.6 \%$, which is 3 and 13 times lower, respectively, than those registered by the USA. The top 10 Asian countries had a share of $96.8 \%$ of the total registered clinical trials and the Republic of Korea had the highest number, at 2,980 trials (27\%) (Figure 1). Among the countries of the WHO SEAR, the majority of the trials were registered by India $(58.8 \%)$ and Thailand $(32.3 \%)$ (Table 1$)$. It was found that there were increasing trends for Asian countries' involvement in phase 3 clinical trials, numbering 7,223 (2001-12), which is $33.4 \%$ of the global share. The trends of registered studies were also increased in the last 12 years in the countries of the WHO SEAR, which are shown in Fig 2. The number of registered phase 3 clinical trials from the SEAR countries was 1626 in the same timeframe (Table 1) which is approximately one quarter of the phase 3 trials of Asian countries and one-fifth of the USA trials.

Asia is home to $60 \%$ of the world's population, and thus shoulders a significant proportion of the global disease

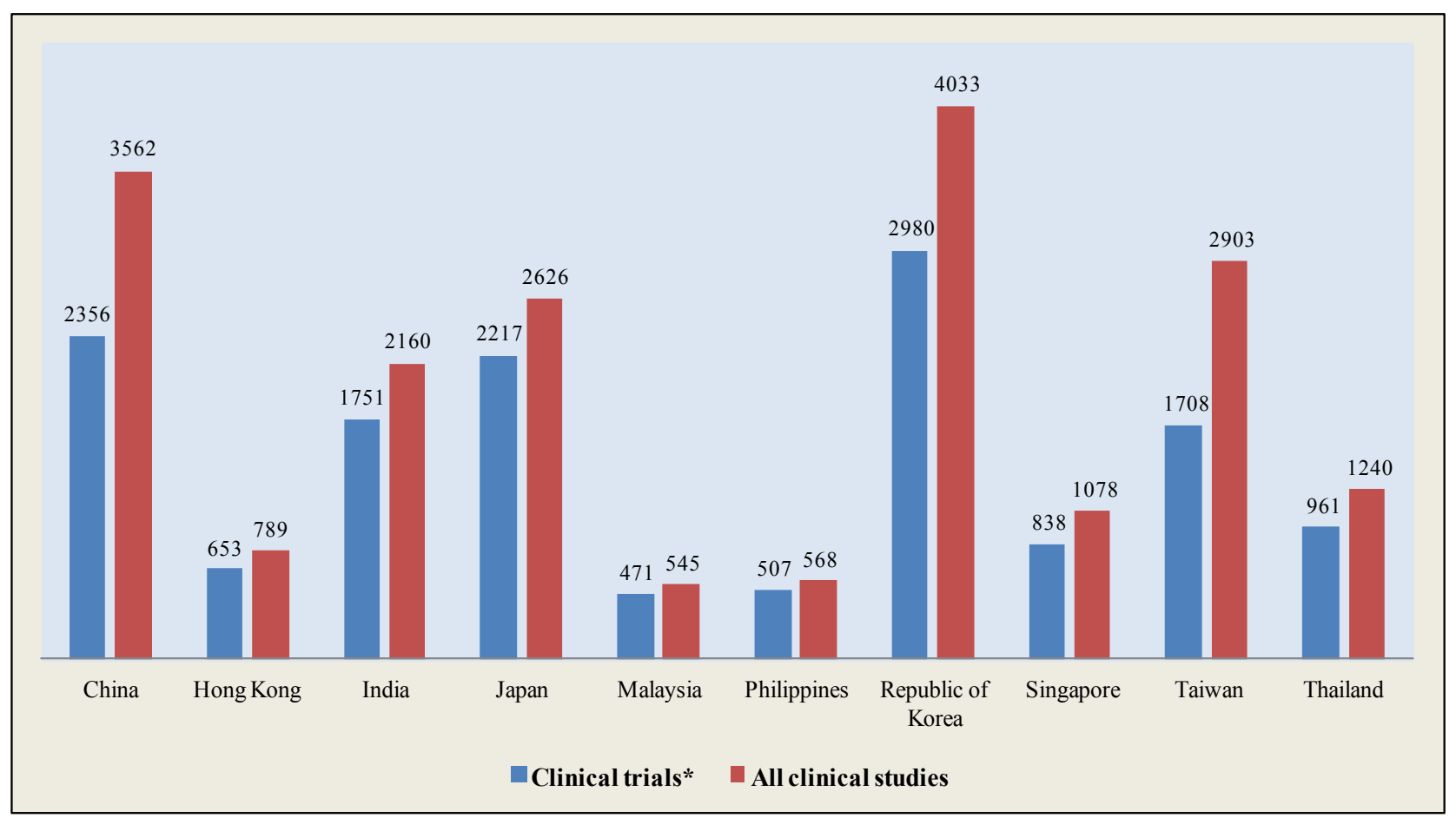

Fig 1: Clinical Trials -10 leading countries in East Asia, South Asia and South East Asia - 2001-12

*Clinical trials- Phase $0-4$.

Correspondence: Dr. Sayeeda Rahman, Lecturer, Department of Clinical Sciences, School of Medical Sciences, University of Bradford, Bradford BD7 1DP, West Yorkshire, UK. E-mail: srahman6@bradford.ac.uk. 
Table 1: Clinical studies registered in WHO SEAR countries - 2001-12

\begin{tabular}{|l|c|c|c|c|}
\hline Countries & $\begin{array}{c}\text { All clinical } \\
\text { studies }\end{array}$ & $\begin{array}{c}\text { Phase 1 clinical } \\
\text { trials }\end{array}$ & $\begin{array}{c}\text { Phase 2 clinical } \\
\text { trials }\end{array}$ & $\begin{array}{c}\text { Phase 3 clinical } \\
\text { trials }\end{array}$ \\
\hline Bangladesh & $141(3.7 \%)$ & $13(4 \%)$ & $26(3.4 \%)$ & $33(2 \%)$ \\
\hline Bhutan & $2(0.05 \%)$ & 0 & 0 & 0 \\
\hline India & $2160(56.9 \%)$ & $237(73.8 \%)$ & $457(59.7 \%)$ & $969(59.6 \%)$ \\
\hline Indonesia & $186(4.9 \%)$ & $7(2.2 \%)$ & $23(3 \%)$ & $84(5.2 \%)$ \\
\hline Korea DPR & $1(0.03 \%)$ & 0 & $1(0.1 \%)$ & 0 \\
\hline Maldives & $1(0.03 \%)$ & 0 & 0 & 0 \\
\hline Myanmar & $7(0.2 \%)$ & $1(0.3 \%)$ & $1(0.1 \%)$ & $4(0.2 \%)$ \\
\hline Nepal & $29(0.8 \%)$ & $1(0.3 \%)$ & $8(1 \%)$ & $9(0.6 \%)$ \\
\hline Sri Lanka & $28(0.7 \%)$ & $1(0.3 \%)$ & $4(0.5 \%)$ & $12(0.7 \%)$ \\
\hline Thailand & $1240(32.7 \%)$ & $61(19 \%)$ & $245(32 \%)$ & $515(31.7 \%)$ \\
\hline Timor-Leste & $1(0.03 \%)$ & 0 & 0 & 0 \\
\hline Total & 3796 & 321 & 765 & 1626 \\
\hline
\end{tabular}

burden and lags behind most other regions in its overall health attainments. Large hospital infrastructures and an increasing pool of trained and motivated clinical researchers have offered a tremendous market potential for clinical trials in the region. These have pulled towards increased pharmaceutical research and offer prospective study sites which provide an opportunity to cost effectively recruit more patients within the timelines of the trial. ${ }^{1-5}$ An important indicator of this is the growing R\&D investment in Asian markets, and CRO services are also forecasted to grow $20 \%$ by 2015. However, there are several factors and problems responsible for the successful implementation of clinical trials in Asia which are related to managerial, ethical, clinical/scientific, regulatory reasons, as well as physicians/investigators and trial subjects. ${ }^{7}$ Managing clinical trials requires efficient trial management strategies including standard trial management guidelines and robust methods of implementation and evaluation, the details of which are shown in Table 2. As markets are expanding in Asia, we have done a SWOT analysis (Table 3) to highlight the positive and negative issues for expanding clinical research markets. It is very encouraging that the opportunities are far greater than threats and that the strengths outweighed the weaknesses. If Asian countries are able to address these issues adequately, the region will be the 'research hub' for all types of clinical trials in near future.

Managing and conducting a clinical trial is complex, so it is crucial that every effort is made to ensure that a trial is implemented effectively and managed efficiently. ${ }^{8} \mathrm{~A}$ huge investment of time and resources in clinical trials should include the proper elements of project planning and management. Trial management is considered as the most crucial amongst the key competencies that are required to deliver high-quality trials. ${ }^{7,8}$ According to the Medical Research Council (UK), the failure of some trials can directly related to trial management problems rather than scientific or trial

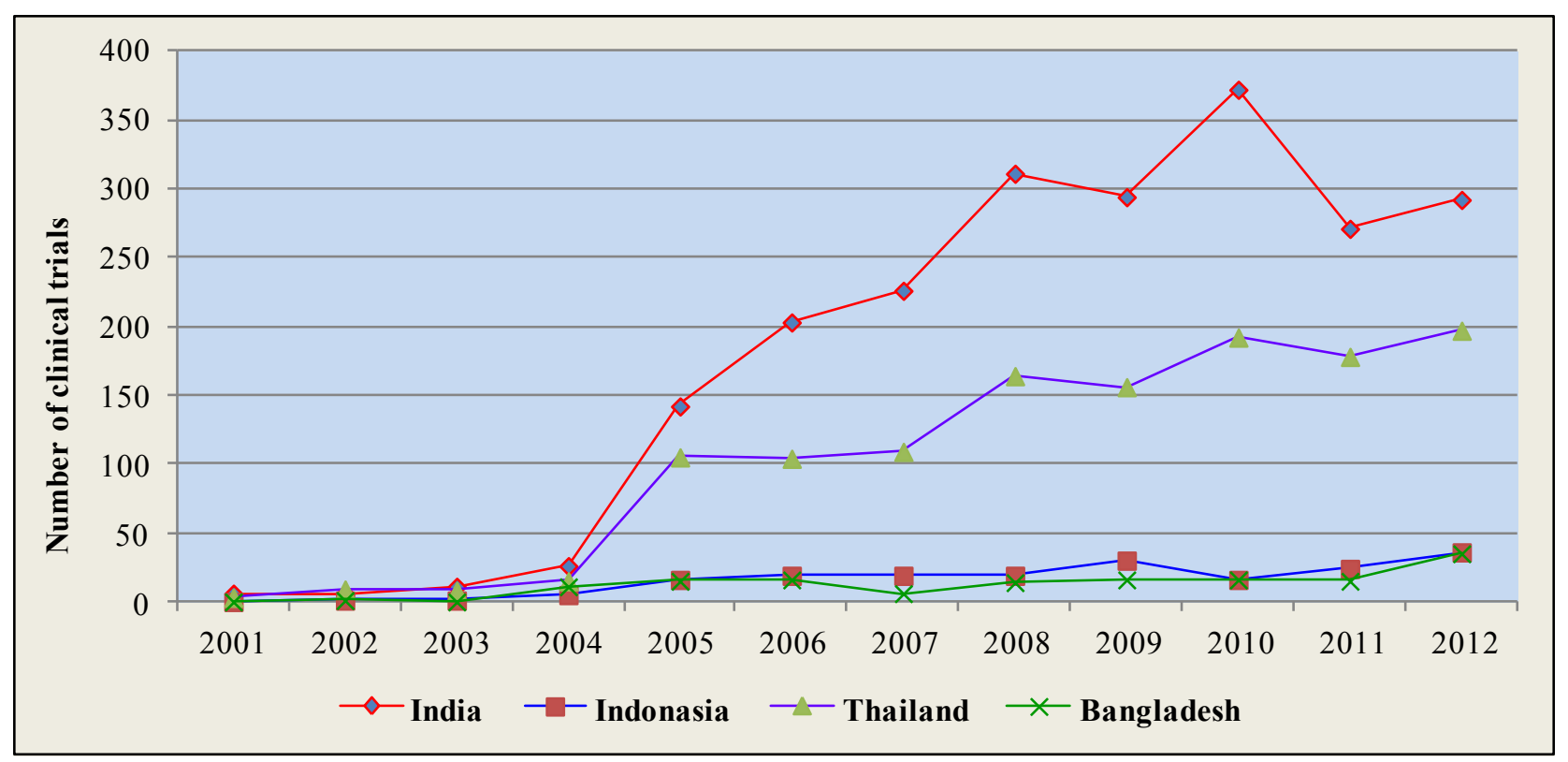

Figure 2: Trend of clinical trials registered in selected WHO SEAR countries - 2001-126

South East Asia Journal of Public Health 2012;2(2):80-84. 
Table 2: Issues and approaches in managing clinical trials

\begin{tabular}{|c|c|}
\hline Key factors & Issues and approaches \\
\hline $\begin{array}{l}\text { Project planning and } \\
\text { management }\end{array}$ & $\begin{array}{l}\text { Strategic and operational management plan } \\
\text { - Objectives, resources, and time frame } \\
\text { - Ethical and scientific issues } \\
\text { - Day-to-day running of the trial } \\
\text { Competent trial team } \\
\text { - Responsibilities: responsibility, authority and delegation } \\
\text { Monitoring - delivered as planned } \\
\text { - Risk assessment, QA management systems and real-time monitoring } \\
\text { Robust statistical analysis plan } \\
\text { Clinical Trial regulations/guidelines } \\
\text { - National/regional/international } \\
\text { - GCP and local regulations } \\
\text { - R\&D facilities and GLP certified labs }\end{array}$ \\
\hline Physician participation & $\begin{array}{l}\text { Time constraints } \\
\quad \text { - Reward and recognition } \\
\quad \text { - Financial: pay increase, promotion, grants for attending conferences } \\
\text { - Non-financial: recognition/awards } \\
\text { Research area } \\
\quad \text { - Physician interest } \\
\text { - Clear potential to improve patient care } \\
\text { Training } \\
\text { Regular feedback }\end{array}$ \\
\hline Patient recruitment & $\begin{array}{l}\text { Provision of greater amounts of information } \\
\text { - 'Hard to reach' patient groups } \\
\text { Patient education about treatment/improving health } \\
\text { - Cutting edge care and latest treatment } \\
\text { Reduce practical issues such as inconvenience, cost } \\
\text { - User-friendly procedures } \\
\text { Incentives } \\
\text { Doctor's influence/recommendations } \\
\text { - Long-standing fear, apprehension, and skepticism } \\
\text { - Clinical trials as an option for treatment }\end{array}$ \\
\hline Collaboration & $\begin{array}{l}\text { Collaborative group or network } \\
\text { Ownership } \\
\text { Involvement and consultation at every stage } \\
\text { Representatives from each participating site } \\
\text { Regular meeting, effective feedback }\end{array}$ \\
\hline Communication & $\begin{array}{l}\text { Method of communication } \\
\text { - Technology: E-mail, SMS, Face-book, twitter, blogs } \\
\text { Listening to problems and resolving any issues quickly } \\
\text { - Regular feedback and staff satisfaction }\end{array}$ \\
\hline $\begin{array}{l}\text { Administrative support to trial } \\
\text { teams }\end{array}$ & $\begin{array}{l}\text { Centralized support services outside the physician group } \\
\text { Clerical and other administrative tasks } \\
\text { - Human subject approvals, institutional agreements } \\
\text { - Progress reports to funding agencies } \\
\text { - Communications among the research team }\end{array}$ \\
\hline $\begin{array}{l}\text { Efficient systems for data } \\
\text { management }\end{array}$ & $\begin{array}{l}\text { Robust computerized systems and procedures } \\
\text { Monitor day-to-day running of the trial } \\
\text { - Recruitment, randomization procedures and data management } \\
\text { - Electronic data capture } \\
\text { - Reduce workload }\end{array}$ \\
\hline $\begin{array}{l}\text { Education and training for trial } \\
\text { team }\end{array}$ & $\begin{array}{l}\text { Degree/diploma/certificate course } \\
\text { Short-term courses: workshops } \\
\text { Online/distance learning }\end{array}$ \\
\hline Publication and dissemination & $\begin{array}{l}\text { Made widely available } \\
\text { - Journals, trial registers, conference presentations } \\
\text { Multi-centre trial } \\
\text { - Local dissemination and presentation } \\
\text { - Standard guidelines for reporting clinical trials }\end{array}$ \\
\hline
\end{tabular}


Table 3: SWOT analysis for emerging clinical trial market in Asia

\begin{tabular}{|l|c|}
\hline Strengths & Weakness \\
Lower trial cost per patient compared to the US and & Lack of awareness about clinical trials/clinical re- \\
EU & search \\
World's largest patient pool with high enrolment po- & Lack of trained clinical research professionals \\
tential & Patients participation and compliance \\
Wider coverage of ethnic populations & Smaller hospitals with inadequate research set-up \\
- Advantage of genetic diversity & Ethical and scientific issues \\
Drug naïve patients & - Delayed project approval process \\
Disease pattern and diversity & Regulatory affairs frameworks and systems \\
Government support and incentives & - Implementation of ICH-GCP and local regulations \\
& Outsourcing risk assessment \\
\hline Opportunity & Threats \\
Emerging markets & Lack of regulatory and ethical approval frameworks \\
Interested international pharmaceutical and biotech & Limited well trained personnel \\
companies & Administrative bureaucracy \\
Large private teaching institutes/ hospitals & Political unrest \\
Fast patient recruitment with relatively low costs & Cultural barriers \\
\hline
\end{tabular}

design problems. ${ }^{9}$ Clinical trials should be viewed from a 'business management perspective' and should include dimensions like 'marketing', 'sales' and 'ongoing client management'. ${ }^{8}$ Regulatory bodies should develop and implement comprehensive regulations for clinical trials and establish monitoring framework to oversee the adherence to the GCP and local regulations. ${ }^{1}$

Physician participation and patient recruitment are the major activities in trial management. ${ }^{7}$ It has been highlighted that physician factors are related to the failure of adequate patient recruitment targets. Trials conducted in the UK showed that $45 \%$ failed to reach $80 \%$ of the target and it is more worrying that less than half of participating physicians succeeded in recruiting any patients. ${ }^{10,11}$ Clinical trials conducted in the UK between 1971 and 2000 (n-333) revealed that just over one-half failed to recruit the desired sample size, one-fifth recruited at least $75 \%$ of the target sample, while a further fifth recruited $25 \%$ of the planned number of patients. ${ }^{12}$ Another concern is that the number of physicians pursuing a career in research has also declined. ${ }^{7,13,14}$ Problems in patient recruitment to a trial may limit the statistical power of the trial to detect a treatment effect, ${ }^{15,16}$ and the reduction in statistical power is considered one of the main reasons for abandoning trials early. ${ }^{17,18}$ In addition, a less representative sample size also reduces the external validity of the trial. ${ }^{15}$ All these problems may thus delay the potential introduction of new treatments and more detailed evaluation of existing ones. ${ }^{15}$ To increase physician participation, the following issues should be adequately addressed: time constraints, doctor -patient relationships, concern for patients, reward and recognition, training, regular feedback and research interests. ${ }^{7}$ Additional demands of the trial, patient preferences, concern caused by uncertainty and concerns about information and consent should also be taken into consideration to increase recruitment/participation of patients. $^{7}$
To be successful, most trials depend on developing some sort of collaborative group or network. ${ }^{8}$ The group should be receive adequate training and support and should take ownership of the project. This ownership will be fostered by involvement and consultation at every stage, from protocol development to publication of the results. Listening to problems, resolving any issues quickly and regular feedback should be central to a trial's communication strategy. Physician-focused structures and forums, research groups, and networks should be created within the academic and healthcare organizations and appropriate collaboration with industry should be established to secure research funds. ${ }^{7}$

A 'centralized support services' outside the physician group should facilitate the business of research by undertaking the clerical and other administrative tasks, including human subject approvals, institutional agreements, progress reports to funding agencies, and communications among the research team. ${ }^{7}$ This will create a research environment that will ensure patient safety, increase economic and medical efficiency, and promote a more standardized and regulatory-compliant process for conducting clinical research. Moreover, this would encourage physicians to take part in the research and contribute directly to the clinical and patient aspects of the trial.

A trial needs robust computerized systems and procedures that monitor every aspect of the day-to-day running of the trial i.e. recruitment, randomization procedures, stock control, data management, data cleaning, and central data monitoring and reporting. ${ }^{7,8}$ Using systems that reduce the number of steps required for data entry, such as the use electronic data capture, can minimize the workload for both investigators and the data management team. ${ }^{8}$

Lack of basic research and training facilities is the main cause of suboptimal utilization of the research intellectual base of the region. ${ }^{7}$ Trial team members should 
receive appropriate education, training and experience which could be a formal qualification or short-term training. Flexible online/distance courses on clinical research should be developed to train health professionals to carry out 'cutting edge' research.

Dissemination of research findings through publications and presentations is also important, ${ }^{8}$ which is lacking among researchers of Asian countries. ${ }^{19,20}$ The issues and approaches related to publication of biomedical research in Asia and the variations among the countries should identified and dealt appropriately. In publications, due credits should be given to all who directly and actively have taken part in the research. ${ }^{8}$ Results of a trial can be made available widely via publishing in journals, books and trial registers, web-sites and presenting in conferences and other forums. Participation of investigators in global and multicentre trials and subsequent publication/presentation motivate them to develop research protocols of international standard and establish a research culture in their own settings. ${ }^{8,19}$

Clinical research is an indispensable part of the drug discovery process to ensure the safety and efficacy of any new drug. In order to successfully navigate the changing nature of drug discovery, all stakeholders related to clinical research must take a proactive approach to shape the emerging market in Asia. The countries of the WHO SEAR should take lesson from India, Thailand and other Asian countries to seize the opportunity for creating the research environment and conducting world class clinical trials. The future is undoubtedly brighter if we take right steps, and in a long run underserved/unserved people in Asia, in particular countries of the SEAR, will be much benefited from new discoveries, better treatments and economic growth.

*Asian countries ${ }^{6}$ : East Asia (China, Hong Kong, Japan, Korea DPR, Mongolia, Republic of Korea, Taiwan); South Asia (Afghanistan, Bangladesh, Bhutan, India, Nepal, Pakistan, Sri Lanka) and South East Asia (Brunei Darussalam, Cambodia, Indonesia, Lao People's DR, Malaysia, Myanmar, Philippines, Singapore, Thailand, Vietnam).

**WHO SEAR (World Health Organization, South-East Asia Region) Countries: Bangladesh, Bhutan, India, Indonesia, Korea DPR, Maldives, Myanmar, Nepal, Sri Lanka, Thailand, Timor-Leste.

\section{References}

1. Louisa M, Takeuchi M, Setiabudy R, Nafrialdi, Takeuchi M. Current status of phase 1 clinical trials in Asia: An academic perspectives. Acta Med Indones- Indones J Intern Med 2012;44:717.

2. Fenn CG, Wong E, Zambrano D. The contemporary situation for the conduct of clinical trials in Asia. Int J Pharm Med 2001;15:169-73.

3. Wong E. Clinical Trials in Southeast Asia: An Update. Drug Inf J 2009;43:57-61.
4. Lang CC. The current status of clinical trials in Malaysia. Drug Inf J 1998;32:1243S-1246S.

5. Toller C. Clinical studies in Asia-Pacific: A regional perspective. J Clin Stud 2013;5:20-23.

6. ClinicalTrials.gov. http://www.clinicaltrials.gov/ ct2/search/map?map=SS (accessed Dec 2012)

7. Rahman S, Majumder MAA, Shaban SF, N Rahman, M Ahmed. Physician participation in clinical research and trials: Issues and approaches. Adv Med Educ Pract 2011;2:1-9.

8. Farrell B, Kenyon S, Shakur H. Managing clinical trials. Trials 2010;11:78.

9. Medical Research Council. Clinical trials for tomorrow. London: MRC, 2003.

10. Jack WJ, Chetty U, Rodger A. Recruitment to a prospective breast conservation trial: why are so few patients randomised? BMJ 1990;301:83-5.

11. Peto V, Coulter A, Bond A. Factors affecting general practitioners' recruitment of patients into a prospective study. Fam Pract 1993;10: 207-11.

12. Vale C, Stewart L, Tierney J; UK Coordinating Committee for Cancer Research National Register of Cancer. Trends in UK cancer trials: results from the UK Coordinating Committee for Cancer Research National Register of Cancer Trials. $\mathrm{Br} \mathrm{J}$ Cancer 2005;92:811-4.

13. Eastman P. Number of US physicians participating in clinical research continuing to drop (Association of Clinical Research Organizations Survey). Oncology Times 2010;32:21-3.

14. Armstrong AY, Decherney A, Leppert P, Rebar $\mathrm{R}$, Maddox YT. Keeping clinicians in clinical research: the Clinical Research/Reproductive Scientist Training Program. Fertil Steril 2009;91:664-6.

15. Fayter D, McDaid C, Eastwood A. A systematic review highlights threats to validity in studies of barriers to cancer trial participation. J Clin Epidemiol 2007;60:990-1001.

16. Baum M. The ATAC (Arimidex, Tamoxifen, Alone or in Combination) adjuvant breast cancer trial in postmenopausal patients: factors influencing the success of patient recruitment. Eur J Cancer 2002;38:1984-6.

17. Ross S, Grant A, Counsell C, Gillespie W, Russell I, Prescott R. Barriers to participation in randomised controlled trials: a systematic review. $J$ Clin Epidemiol 1999;52:1143-56.

18. Holden G, Rosenberg G, Barker K, Tuhrim S, Brenner B. The recruitment of research participants: a review. Soc Work Health Care 1993;19:1-44.

19. Majumder MAA. Issues and priorities of medical education research in Asia. Ann Acad Med Singapore. 2004;33:257-63.

20. Majumder MAA, Rahman S, Shaban SF, N Rahman, Islam Z. A. PubMed-based quantitative analysis of biomedical publications in the SAARC countries: 1985-2009. J Coll Physicians Surg Pak 2012;22:1-7. 